\title{
Isotope hydrobiochemical characterization of solutions in permeable coastal sediments affected by submarine groundwater discharge, southern Baltic Sea.
}

CATIA MILENE EHLERT VON AHN ${ }^{1}$, PETER ESCHER ${ }^{1}$, BEATA SZYMCZYCHA ${ }^{2}$, IRIS SCHMIEDINGER ${ }^{1}$, ULRICH STRUCK $^{3}$, BO LIU ${ }^{4}$, SUSANN VOGLER ${ }^{1}$ AND MICHAEL E. BÖTTCHER ${ }^{1,5,6}$

${ }^{1}$ Leibniz Institute for Baltic Sea Research (IOW), Geochemistry \& Isotope Biogeochemistry Group, Department Marine Geology

${ }^{2}$ Institute of Oceanology, Polish Academy of Sciences

${ }^{3}$ Free University of Berlin

${ }^{4}$ Section of Marine Geochemistry, Alfred Wegener Institute Helmholtz Centre for Polar and Marine Research

${ }^{5}$ Marine Geochemistry, University of Greifswald

${ }^{6}$ Interdisciplinary Faculty, University of Rostock

Presenting Author: catia.vonahn@io-warnemuende.de

Submarine Groundwater Discharge (SGD) acts as a source of fresh water and dissolved substances for coastal ecosystems, but its fluxes may strongly depend on the benthic water-solidmicrobe interactions close to the sediment-water interface. The present study addresses the impact of near-shore SGD on the biogeochemical process at the sediment-water interface in Puck Bay (PB), southern Baltic Sea, by evaluating chemical gradients where SGD was identified. Field campaigns, carried out from 2009 to 2019 , comprised water column, porewater and, sediment sampling at sites with and without SGD impact. Samples were analyzed for stable isotopes $(\mathrm{H}, \mathrm{O}, \mathrm{C}, \mathrm{S})$, nutrients, dissolved inorganic and organic carbon, major and trace elements analysis. In addition, the data are compared to groundwater from wells on land close PB and at the Hel peninsula, the northern boundary of PB. Porewater gradients of salinity and conservative elements at SGD sites show an advective upward flow of freshwater in sandy sediments and diffusion-dominated behavior in muddier sediments. The upward transport of freshwater controls the hydrochemical gradients, e.g. a downward increase of metabolites like DIC and nutrients. The porewaters at the SGDimpacted site are essentially depleted in dissolved sulfate at depth, whereas the shallow porewaters and the not-impacted sites had higher concentrations, mainly derived from mixing with brackish bottom waters from $\mathrm{PB}$. Porewater $\delta^{13} \mathrm{C}_{\mathrm{DIC}}$ values ranging between -20 and $0 \%$ show a non-conservative behavior, indicating active carbon cycling in the surface sediments. Possible sources for DIC are groundwater and oxidized organic material. Values for the seeping groundwater at Hel peninsula, calculated by a two end-member mixing model, show isotope values around $\delta^{18} \mathrm{O}=-11$ and $\delta \mathrm{D}=-77 \%$, results that are lighter than literature values for Holocene meteoric waters for this area. Hence, SGD impacted sediments need a clear understanding of process taking place in order to evaluate the associated chemical fluxes to coastal waters. 